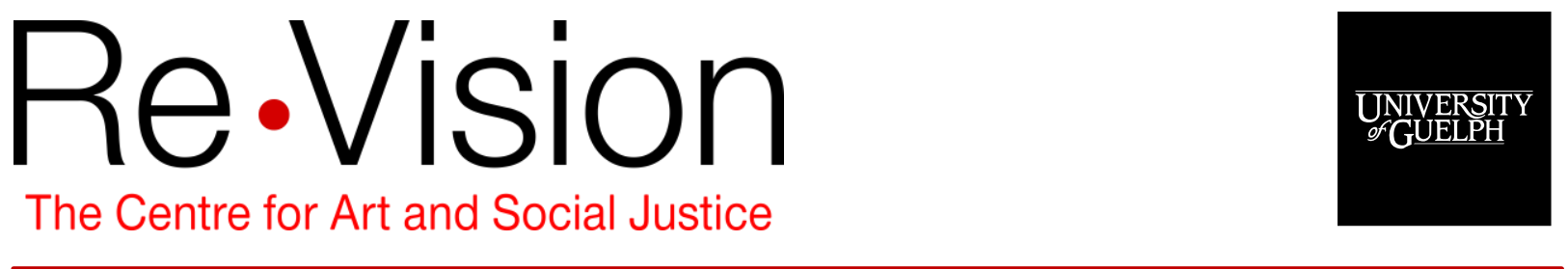

\title{
Eating disorder prevention as biopedagogy
}

Andrea LaMarre

University of Guelph

Carla Rice

University of Guelph

Glen Jankowski

Leeds Beckett University

This is an Accepted Manuscript of an article published by Taylor \& Francis in Fat Studies: An Interdisciplinary Journal of Body Weight and Society on March 1, 2017, available online:

https://www.tandfonline.com/doi/full/10.1080/21604851.2017.1286906

\section{Recommended citation:}

LaMarre, A., Rice, C., \& Jankowski, G. (2017). Eating disorder prevention as biopedagogy. Fat Studies: An Interdisciplinary Journal of Body Weight and Society, 6(3), 241-254.

https://doi.org/10.1080/21604851.2017.1286906 


\section{Eating Disorder Prevention as Biopedagogy}

Andrea LaMarre, Carla Rice, \& Glen Jankowski

\section{ABSTRACT}

The authors describe eating disorder prevention as biopedagogy: that is, as a set of expectations for how to manage one's body and self to be a healthy productive citizen. This biopedagogy lands differently on different "bodies of risk"-those of people coded as at risk for eating disorders and those coded as at risk for "obesity" in a social milieu that marks certain bodies, such as those of different sizes, sexualities, ethnicities, socioeconomic statuses, genders, and abilities-as unacceptable. In theorizing eating disorder prevention as biopedagogy, the authors consider not only the content of prevention messages, but also conventional notions of the normative self that underpin these messages and hence the form that they take, and how this form conflicts with critical perspectives that view subjectivities as dynamic and in flux. The authors argue for a shift to body becoming pedagogies grounded in social justice and intersectional perspectives, suggesting that systemic changes are needed to make diverse bodies welcome.

\section{KEYWORDS}

Biopedagogies, eating disorders, feminism, prevention, social justice

Moralizing messages for health circulate around bodies through school classrooms, clinics, media, and families, shaping understandings of how we need to scrutinize and contour our bodies to be productive 
"biocitizens" (Evans \& Rich, 2011). Foucault (1978) called the subtle and diffuse power that compels individuals to manage their own health and risk "biopower." Critical scholars have explored "biopedagogies," instructions for bodily management imbued with moral implications for how we act (Wright, 2009). Biopedagogies circulate throughout "totally pedagogised societ[ies]" (Bernstein, 2001, p. 365)—societies wherein knowledge has become decontextualized and commodified. In this context, biopedagogies define which "bodies have status and value" (Evans \& Rich, 2011, p. 367) using culturally and biomedically informed binary criteria like healthy/unhealthy, fit/unfit, and normal/abnormal. Because they rely on normative (White, Western, able-bodied, and masculine) standards of the fit, healthy, and productive body, biopedagogies create an unfit, unproductive, and abnormal bodily other, marked by gender, race, disability, and size differences (Rail \& Jette, 2015). These binaries influence people's conceptualizations of themselves as healthy productive citizens throughout their lives, becoming lenses to evaluate all bodies.

In this article, we consider how eating disorder prevention messages operate as biopedagogies and intersect with "anti-obesity" biopedagogies to perpetuate stereotypes about who is "at risk" for body and food distress. We explore relationships between eating disorder and "obesity prevention" biopedagogies, unearthing assumptions that underpin, and interfere with, eating disorder prevention efforts. Engaging with biopedagogies means critically and systematically exploring how bodies are surveilled, coded, and disciplined under contemporary, Western, neoliberal capitalism. We propose "body becoming pedagogies" (Rice, 2014, 2015) as a way of recognizing difference as fundamental to the world, honoring complexity 
and process in the materialization of bodies and practices of eating. These pedagogies allow us to untether eating practices from body size in ways that promote wellness in people of all sizes.

\section{Biopedagogies in the totally pedagogized society}

Bernstein (2001) theorized that information societies-those in which knowledge becomes objectified and commodified-are totally pedagogized as states and markets institute "systems of control from instruction" in social relations at every site of life (MacNeill \& Rail, 2010, p. 179). These circulating knowledges compel citizens to become hyperflexible learners to sped-up life under neoliberal capitalism (Gewirtz, 2008). Neoliberal capitalism promotes rationality grounded in political economy, which makes individuals responsible for their lives, health, and happiness (Brown, 2005). Neoliberal capitalism reflects a retreat of the state from social policies but also extends beyond traditionally "political" arenas-for instance, into classrooms and households-obscuring the site(s) of origins of pedagogies as well as the political interests that they serve.

Totally pedagogized societies give rise to biopedagogies-subtle and diffuse instructions about bodily management and conduct (Wright, 2009) that work in, through, between, and around bodies (Foucault, 1978). Within such neoliberalized, pedagogized contexts, imperatives for health that aim to create a fit, productive, and self-sufficient biocitizenry also construct ostensibly weak-willed, unruly, and irrational others-people who reject healthy lifestyles or fail to conform to normative standards for healthy bodies (Francombe-Webb \& Silk, 2015; McPhail, 2013). Working class, Indigenous and racialized people, immigrants, queer and trans people, 
women, disabled individuals, and non-Europeans have been measured, contrasted, and pronounced deficient under the European Enlightenment project that held up affluent White men's embodiments as a norm against which to judge who qualified as human and citizen (Braidotti, 2013). These groups continue to be the target of sexist, homophobic, classist, ableist, racist, and colonialist biopedagogies that oppress marginalized bodies (Rail \& Jette, 2015).

"Anti-obesity" biopedagogies hinge on the neoliberal assertion that each individual is responsible and accountable for their own health; fatness, therefore, is seen as borne of individual choices (FrancombeWebb \& Silk, 2015). This association underpins behavior change models that posit simple, linear, and mechanistic relationships between knowledge, behavior, and health. Under this optic, certain groups of people are marked as being ignorant of "health" measures (calories, body mass index, etc.) they might enact to achieve a more normative body. These measures potentially influence stereotypes around who is at risk for restrictive or binge-purge-type eating disorders and obesity. For example, those from middle to upper classes may be assumed to "know better" than to engage in behaviors assumed to result in fatness (McPhail, 2013). Accordingly, we expect that messages about bodies and health designed to prevent eating disorders will land differently on different bodies.

\section{Eating disorder prevention as biopedagogy}

Cliff and Wright (2010) termed contemporary school-based curriculum messages of "anti-obesity" and anti-eating disorder "confusing and contradictory." They explore body pedagogies as these operate in 
health and physical education (HPE) in Australian school systems, illustrating how eating disorder prevention becomes sidelined in the face of concerns about "obesity." Sharing these scholars' concerns about conflicting messages delivered in HPE, we argue that, whether school based or not, eating disorder prevention programs/campaigns operate as biopedagogies. We contend that eating disorder prevention biopedagogies conflict not only in content, but in form, with "anti-obesity" biopedagogies. Eating disorder prevention is primarily delivered through dissonance induction, wherein people are given empirical information about food, weight, and bodies (dangers of dieting, unrealistic beauty ideals) that directly challenges "anti-obesity" biopedagogies. We argue that this delivery assumes that a unified subjectivity is both possible and desirable; it fails to consider how split subjectivities can act as protective against the inherent contradictions of neoliberal capitalism.

\section{Trajectories of eating disorder and "obesity" prevention}

Decades-old research reveals that eating disorders can affect anyone (e.g., Bordo, 2003); however, the stereotype of the thin, White, middle-toupper class, cisgender, heterosexual, young girl as "eating disorder patient" persists. Those who do not fit the expected picture, including queer, disabled, racialized, and otherwise marginalized people, as well as men, are largely presumed to be at lower risk, or immune (Jones \& Malson, 2011). With a few exceptions (Burrows \& Cooper, 2002; Lebow, Sim, \& Kransdorf, 2015; Rice, 2007), the stories of fat people struggling with eating disorders are notably missing from the eating disorders literature-unless "obesity" is presented as an eating disorder, rather than a problematic, medically defined category of body size. Both thin and fat bodies are 
framed as bodies of risk in popular discourse (Saguy \& Gruys, 2010). However, the types of risk used to encode these bodies differ. Bodies coded as risky are approached differently by preventionists-while both eating disorders and "obesity" are to be prevented, and there have been efforts to combine eating disorders and "obesity prevention," currently both prevention forms are communicated differently and make different assumptions about bodies, health, and food.

Similar to other health messaging, eating disorder prevention programs are implicated in the individualizing of social issues and responsibilization of bodies. To provide a blanket statement about what eating disorder prevention looks like across different formal and informal educational sites across the life span would elide the different pedagogical approaches preventionists have taken in delivering such programs. However, many prevention initiatives share characteristics that illustrate the idea of an eating disorder prevention biopedagogy. A thorough review of eating disorder prevention literatures is beyond the scope of this article; we offer instead as caveat the acknowledgment that there are examples of programs that critically engage with how all bodies are situated within sociopolitical milieu (Larkin \& Rice, 2005).

Eating disorder prevention efforts have traditionally entailed bolstering protective factors and reducing risk factors for distress around food and bodies. Preventionists have targeted thin ideal internalization, body dissatisfaction, dietary restraint, dieting, negative affect, and bulimic symptoms, among other proposed risk factors (Stice, Chase, Stormer, \& Appel, 2001). Often, prevention targets thin ideal internalization, which is thought to predict negative appearance evaluation, body dissatisfaction, 
and disordered eating (Stice, Shaw, \& Marti, 2007). Some programs opt to primarily bolster protective factors against body and food distress, including self-esteem and body satisfaction (McVey, Davis, Tweed, \& Shaw, 2004).

These factors have been addressed through a number of strategies, including media literacy and dissonance induction. Earlier prevention efforts tended to use didactic strategies, such as identifying problematic media imagery and detailing clinically recognized (i.e., diagnosed) food and body distress behaviors. More recently, dissonance induction-which entails engaging individuals to publicly and repeatedly reject an idea that they previously endorsed (e.g., that appearance ideals are desirable)—has become the "gold standard" of eating disorder prevention.

Since the advent of "obesity epidemic" rhetoric, researchers have sought to combine eating disorder and "obesity prevention." Advocates of a combined approach argue that integrated approaches can address ostensible shared risk factors, including dieting, body dissatisfaction, media consumption, depressive symptoms, and emotional regulation (Wilksch \& Wade, 2013). These approaches capitalize on societal fears of fatness and concerns about exercise and eating to mobilize support for a combined strategy. Integration advocates may also wish to reconcile contradictory messaging given to caregivers, health care providers, teachers, and others about how to manage growing bodies (e.g., whether to promote weight loss in larger children during the growth process or leave their physical development alone without weight-based intervention; Irving \& NeumarkSztainer, 2002). Further impetus for integration comes from efforts to avoid blunt "obesity" prevention messaging that is demonstrably more harmful than helpful as it deepens stigma against larger bodies (Bacon \& 
Aphramor, 2011; Rice, 2015). Given the current focus on "anti-obesity" efforts, integration may be a way to maintain the voice of eating disorder preventionists amid clamorous "anti-obesity" missives. However, as Cliff and Wright (2010) noted, this integration may result in "discursive confusion and a kind of practical paralysis [sic] [...] as the teacher and students attempt to make sense of the different biopedagogies and their implications for 'knowing about' food and bodies" (p. 230).

Since Cliff and Wright's (2010) analysis, efforts to responsibilize citizens for their bodies and combat the "obesity crisis" have only intensified. As Cameron et al. (2014) noted, "these dominant discourses (e.g., 'it's up to you,' 'save the child,' and 'obesity crisis') have powerful effects on how bodies are produced and controlled in society and schools" (p. 695). Even when the problematics of body ideals are contested, biopedagogical strategies for generating healthy bodies can carry the weight of exclusionary politics and healthism, inordinately targeting those in marginalized bodies. Perhaps most importantly, the kind of power circulating by way of biopedagogies in totally pedagogized societies is, as Bernstein and Foucault have noted, largely invisible-it gains traction not through coercion or force of imposition, but by people self-regulating in relation to the mythical (male, masculine, White, heterosexual, thin, ablebodied) norm.

\section{Split subjectivities and dissonance induction}

To draw out the problematics of an eating disorder biopedagogy in light of dominant "anti-obesity" biopedagogies, we turn our focus to methods of delivery. Notably, dissonance induction has been the "gold 
standard" approach for eating disorders prevention at all levels of education, from elementary to university and into the community and larger culture (Stice, Shaw, \& Marti, 2007). Building on earlier media literacy approaches, dissonance induction implicitly contends that a healthy subjectivity is a unified one, in which a person can reconcile their thoughts with their actions. Dissonance induction in the eating disorder prevention field is premised on the idea that having people critique dominant discourses about bodies (e.g., ideal embodied femininities) will result in discomfort should these individuals later espouse or aspire to such ideals. In light of their coexistence with "anti-obesity" biopedagogies, we ask a number of questions about the long-term effectiveness of these programs. First, does critiquing bodily ideals mean that one necessarily no longer desires an ideal body? Second, is it possible to be highly media literate but nonetheless fail to resist media pressures? Third, is it likely that people might successfully integrate or even just espouse such critiques in certain times/places and fail to do so in others? Finally, is literacy immunity?

We contend that the answers to the above questions is no. Literacy is not immunity from the affective experience of living in a body in a society where few bodies are deemed fit or even "normal." We are not arguing that dissonance induction can never be effective-certainly, programs based on a dissonance model may reduce thin-ideal internalization, body dissatisfaction, dietary restraint, bulimic pathology, and negative affect (Stice, Chase, Stormer, \& Appel, 2001), which could be considered an important first step in improving our collective food and body distress. However, these strategies alone are insufficient for sustaining more positive strides in body acceptance. 
Returning to how "anti-obesity" biopedagogies relate to eating disorder prevention biopedagogies, we might consider how efforts to combine eating disorder and "obesity" prevention frequently leave underexplored the ways in which "anti-obesity" policies, though wellintentioned, essentially call for the erasure of fat bodies (O'Reilly \& Sixsmith, 2012). Here, fat bodies are constructed as a stop on the way to a physique that fits within the narrow confines between too large and too small. Looking at the intersection between eating disorder and "antiobesity" biopedagogies reveals how a certain amount of dissonance may actually be a normal response to conflicting sets of instructions about body management. Some bodies will never fit into the heavily bounded and surveilled middle ground between fatness and thinness: regardless of their engagement with "health behaviors" (Bacon \& Aphramor, 2011).

It would be a mistake to frame the split and fluctuating subjectivities, palpable in those of us exposed to conflicting healthist prevention messages, as a sign of pathology. Rather, our split subjectivities might be a protective mechanism; splitting or alternating between contradictory sets of values and desires may be a way for us to shield ourselves from the most harmful effects of biopedagogies. Making certain concessions (deciding what types of body modification to engage in, when and how) may enable some individuals to feel confident enough or earn enough privilege in interactions to protect "against extreme dissatisfaction with the body" (Murnen \& Smolak, 2009, p. 193). This protection is not about completely transcending bodily shame or discontent (Rice, 2014); it is about recognizing that we might come to understand the multiple ways in which biopedagogies are problematic for ourselves and others while also feeling 
their sway. We might acknowledge, when exploring biopedagogical messages about food and bodies, how under structural conditions of neoliberal capitalism, we are never fully in step with the commodities we are being peddled. The character of neoliberal capitalism is its capacity to seduce us into continual striving toward a commodified ideal (Braidotti, 2013). Poststructuralists assert that paradoxical cultural discourses make up our subjectivities; here, we assert that subjectivities-and bodies-are not unitary or singular, but multiple, unfinished, and continuously in flux.

\section{Beyond biopedagogies: Embracing social justice and opening possibilities for being}

Thus far, we have considered how eating disorder prevention messages act as biopedagogy characterized by injunctions to self-manage to maintain a unified subjectivity and avoid pathology. This biopedagogy lies in stark contrast with the lived realities of fat people, whose stories are often missing from literature detailing the "successes" of eating disorder prevention. This omission particularly applies to those whose bodies are multiply marginalized, despite recent population-based studies showing that eating disorders may be rising among racialized, queer, disabled, working class and transgender young women and men, among others (e.g., Feldman \& Meyer, 2007). How such differences might meaningfully be integrated into ongoing prevention efforts has not hitherto been given serious consideration.

\section{Embracing social justice}

To move beyond a biopedagogy of eating disorder prevention and toward sustainable, effective and more inclusive prevention, we must 
consider how marginalized people are differently impacted by these biopedagogies: who is the audience for these biopedagogies, and how do these biopedagogies intersect with lived bodily realities? The long-term effects of prevention are limited if they do not also attend to broader factors, including (a) people's ability to access prevention; (b) how well prevention messages resonate with marginalized cultural practices (e.g., queer and ethnoracial minority perspectives); (c) the extent to which prevention recognizes that people may carry not one but multiple and contradictory sets of cognitions, emotions, and desires about their bodies; and (d) the absence of a broader social justice and advocacy agenda that works against body normalization, pathologization, and commodification. We encourage an intersectional orientation toward eating disorder prevention that would attend to the need for prevention efforts to be socially just if they are to be effective for, and embracing of, marginalized people's bodies and bodily experiences. We also challenge the idea that "obesity" prevention should be attempted at all given that it reinforces the vilification of fat and ultimately calls for the erasure of fat bodies.

The consequences of ignoring people's intersectional discriminations and privileges are significant. While a peripheral acknowledgment of the intersection between marginalization and embodiment operates in some of the eating disorder literature, this work risks essentializing difference. Essentialism refers to the idea "that there is a single woman's, or Black person's, or any other group's, experience that can be described independently from other aspects of the person-that there is an 'essence' to that experience" (Grillo, 1995, p. 19). Essentialism around risk and vulnerability for eating disorders and "obesity" oversimplify complex bodily 
experiences. For example, consider the African American woman who reports shame for developing anorexia that eating disorder professionals and others tell her she is immune to. Consider also gay men, whose particular vulnerability to food and body distress has been explained by researchers as tied to obsession with appearance in gay male communities (for a review of this issue, see Kane, 2010). These essentializing perspectives presume that being Black or gay itself makes one immune/vulnerable to food and body distress, eschewing the influence of the discrimination and stigma associated with these embodied identities. Ignoring these and other intersections may result in underplaying or ignoring suffering (Crenshaw, 1991).

How might we begin to bring an acknowledgement of compounding marginalizations into eating disorder prevention? Doubtless, it takes thought, time and training to teach intersectionality in relation to eating disorders (and to teach about eating disorders intersectionally). But as soon as we start to expand the discussion of bodies beyond size, to ethnicity, gender, and so on, we begin to implicate intersectionality in our discussions of eating disorder prevention. Working intersectionally allows us to begin to challenge tendencies toward essentialization and generalization. After all, a Black fat body will be read differently than a White fat body, as will a fat women's body compared to a fat man's body (Rice, 2014).

Acknowledging these intersections is important, but it is equally important to focus on the sources of such readings. Too often, in discourse around eating disorders in general and prevention in particular, focus is placed on the individual and any acknowledgment of culture is reduced to 
media (Gill, 2008). Where "other cultures" (non-Western, non-White, nonhegemonic) are recognized as playing a role in mitigating or provoking eating disorders, they are often understood as static, rather than as dynamic and as influencing even as they are being influenced by other cultures and conditions. Moreover, while media are certainly a part of culture, and while media consumption may lead to negative body image, culture is more than media, particularly if we take an intersectional approach to understanding the intertwining of bodies and marginalizations. It is also important not to treat participants as unduly vulnerable to a toxic culture or as cultural dupes should they endorse normative orientations toward body ideals (Bordo, 2003; Gill, 2007). Culture is not a top-down, one-way force and people are not mindless, vulnerable consumers of it. Gill (2007) advocates a balance, asking researchers to critically respect participants' perspectives; to acknowledge participants' own expertise over their embodiment, while also situating those embodiments within the wider context that all people, both researcher and participants included, have to contend. It is this context, made invisible by neoliberal capitalism (Bordo, 2003; Gill, 2007), that constrains people's choices regardless of their behavioral expression.

We must move beyond focusing on the individual to a broader view of how people live in relation to others and in diverse social circumstances. What systematic factors contribute to food and body related distress? Under capitalism, profits are valued above people, and often at the expense of well-being. Can we bring this awareness into our prevention efforts to scaffold a critique that leads not just to media literacy but to a 
radical rethinking of the drivers that lie behind media imagery and biopedagogies?

Specifically, it is important to consider the problematic trend where companies such as Dove, Weight Watchers, and Special K appear to have embraced anti-body-distress advocacy at the same time that they promote their weight loss-related product. Special K's "Own It" campaign, for instance, exhorts women to love their bodies, whereas the Special K Diet promotes eating very few calories per day. Weight Watchers encourages women to reclaim their lives (through dieting) but simultaneously suggests, in their recent advertisements, that fat women are not sexual beings. This cooption must be on preventionists' radar as, perniciously, what can appear to be small gains may actually be big losses for prevention. These campaign produce "Love Your Body" discourses (Gill \& Elias, 2014)— discourses that Rice (2014) argued dictate how a woman now must not only contend with the usual food and body related distress but also have a pronounced, overt, and constant love for her body lest she be considered a bad role model for others. As well as being a further dictation for women, this can also silence the food- and body-related suffering people wish to speak about, and the intersections of social location that result in different embodied experiences that cannot simply be divided into "good" or "bad," "healthy" or "unhealthy," "normal" or "abnormal". By focusing on the individual and selling products as the only solution to food and body distress, these discourses place the onus of problem solving on the individual, glossing over the complex interplay of consumerism, neoliberalism, and relations of privilege and marginalization that undergird food and body distress. 
Love Your Body discourses relate back to Bernstein's (2001) theory of information societies, which posits that processes of continuous pedagogization produce "socially empty" selves (p. 366). Singh (2015) argued that the "socially empty self" does "not simply [internalize] the message of neoliberal economic performativity" (p. 375), but may instead become "an ambivalent, uncertain self, torn between the desire for more knowledge and the paradoxical emptiness and uncertainty that such longing brings" (p. 378). Singh's elaboration of Bernstein's theory is particularly relevant to understanding how and why people in relatively affluent, consumer-oriented cultures might come to occupy ambivalent and uncertain subject positions in relation to contradictory commodified discourses of body love versus body improvement. Though many of us critique such discourses from feminist or other political vantage points, we might also feel drawn to experiment with them out of a sense of uncertainty and anxiety about our own subjectivities.

\section{Toward body becoming pedagogies}

We suggest a move toward body becoming pedagogies as a way of extending beyond individualizing biopedagogies. Body becoming pedagogies are scaffolded in an embodied ethics-that is, an attunement to people's embodied experiences, or the stories people tell about their bodily experiences and the way these stories and the bodies that tell them are situated in sociopolitical and economic milieu (Rice, 2015). As opposed to biopedagogies, which prescribe what bodies are, should be, and will become (if people follow health instructions), body-becoming pedagogies open possibilities for living with difference differently. Body becoming pedagogies are promising as they offer opportunities to work toward 
prevention of bodily discontent not through minimizing dissonance between actual and ideal bodies - a strategy that may dismiss the fact that some people's bodies are not currently welcome in our society—but through welcoming in the complexity, multiplicity, and transgressive nature of bodies in motion.

Body becoming pedagogies invite us to probe the multifaceted nature of people's subjectivities; they open space for thinking creatively about how to promote "body satisfaction" and resolve body and food distress (Rice, 2015). For instance, we might move the emphasis from individuals to the place where the body, psyche, and society meet, shifting the focus from changing bodily selves to creating equitable school and other institutional and broader cultures. In a school setting, this approach could involve implementing peer-generated rules against body-based harassment for the whole student body; it may involve inviting parents and teachers to explore any food or appearance related difficulties of their own; equally, it could involve the creation of policies aimed at tackling harassment or promoting appearance diversity in a community environment (Larkin \& Rice, 2005). Indeed, body becoming pedagogies might be enacted together with intersectional approaches whenever we work toward fostering a critical space where different kinds of knowledge are valued and different voices are registered. In a collaboratively designed, intersectional prevention strategy, preventionists and participants teach and learn through recognizing each others' positionalities and experiences. To do this, it is important to understand the complex origins of body distress and to move beyond simplistic associations between "culture" (often reduced to "media" 
or when spoken of in relation to marginalized communities, assumed to be static) and disordered eating.

Body becoming pedagogies entail moving from moralizing biopedagogies toward a "body equity" approach in eating disorder prevention. For instance, Rice and Russell (2002) used a "body equity" approach to health promotion: rather than beginning with the individual and moving outward to the rest of the school ecology, they targeted stigma around weight that perpetuated body and food distress. They argued that before people could integrate prevention messages into their lived realities, preventionists needed to systemically consider and address how stigma materializes around certain bodies of risk. This approach encourages a focus on systems, rather than individuals, facilitating bodily comfort by altering environments to provide options and acceptance rather than changing individuals. To take their focus on promoting equity even further, educators might, for example, open up the parameters of what constitutes "fitness" and how to get there in physical education classes; for instance allowing for activities from yoga to swimming to table tennis. A body becoming pedagogy challenges binaries that privilege some bodies over others, doing so in a way that invites consideration of the multiple aspects of embodiment that impact people and the multiple potentialities for being/becoming unique to their different bodies.

Healthy skepticism around the pernicious operation of consumer capitalism in and around eating disorder prevention efforts is important; transforming awareness into action will help prevention stick. Moving forward entails attending to bodies in interaction with the forces identified previously. Embodying prevention means going beyond the reflected 
surface of the body image toward understanding how people engage with their bodies and their cultural contexts at multiple levels (e.g., efforts that emphasize the pleasures of other sensory experiences and looking inward toward the felt body might sustain greater gains in prevention). Body becoming pedagogies aim to raise consciousness about how our experiences in and decisions about our bodies are always necessarily tied to how our bodies are framed in society; that "the ideal of the healthy, able, and in-control body is a temporary state and that the abject will always return whether in aging, disability, disease, fatness, or other "transgressions" of norms" (Rice, 2015, p. 6). Change occurs then not within individuals to conform, but rather through collectively challenge biopedagogical framings of sexed, classed, sized, racialized bodies.

\section{Conclusion}

Acknowledging the assumptions that have pervaded extant approaches to prevention while honoring the work of those who have been pushing toward body acceptance is a critical move for the prevention field. To move forward, it will be important to create the space to attend to individuals' diverse embodiments, situated as they are in sociocultural milieu. We acknowledge how preventionists have made strides toward increasing societal awareness of the potential seriousness of body image concerns and disordered eating. However, as critical scholars we encourage moving beyond an individualizing approach. Future researchers should investigate the lived impact of the biopedagogy of eating disorder prevention and bring the stories of those living in larger and multiply marginalized bodies to the fore. 
Acknowledging that eating disorder prevention can itself be biopedagogical and attending to intersectionality are key to moving beyond a myopic focus on thin-ideal internalization that may result in short-term gains but leave participants feeling caught in-between personal convictions and broader sociocultural contexts. We must be wary around prevention that maintains a consumerist focus, coopting "body positivity." We must also actively challenge broader systemic structures that cause many harms including food and body distress (e.g., poverty). We encourage a move beyond simplistically melding eating disorder and "obesity" prevention strategies, acknowledging the tensions inherent to doing this work in a society that seeks to erase fat and otherwise marginalized bodies.

Recognizing how these systems might differently impact variously embodied individuals may help us to put culture back into sociocultural context and to orient ourselves to the challenges we still face in attempting to prevent body and food distress. This recognition can move us toward a body becoming pedagogy that allows different bodies to flourish and for systemic changes to enable that flourishing.

\section{References}

Bacon, L., \& Aphramor, L. (2011). Weight science: Evaluating the evidence for a paradigm shift. Nutrition Journal, 10(1), 9.

Bernstein, B. B. (2001). From pedagogies to knowledges. In I. Neves, A. Morais, B. Davies, \& H. Daniels (Eds.), Towards a sociology of pedagogy: The contribution of Basil Bernstein to research (pp. 363378). New York, NY: Peter Lang. 
Bordo, S. (2003). Unbearable weight: feminism, Western culture, and the body. Oakland, CA: University of California Press.

Braidotti, R. (2013). The posthuman. Oxford, UK: Polity Press.

Brown, W. (2005). Edgework: Critical essays on knowledge and politics. Princeton, NJ: Princeton University Press.

Burrows, A., \& Cooper, M. (2002). Possible risk factors in the development of eating disorders in overweight pre-adolescent girls. International Journal of Obesity Related Metabolic Disorders, 26, 1268-1273.

Cameron, E., Oakley, J., Walton, G., Russell, C., Chambers, L., \& Socha, T. (2014). Moving beyond the injustices of the schooled healthy body. In I. Bogotch \& C. Shields (Eds.), International handbook of educational leadership and social(in)justice (pp. 687-704). New York, NY: Springer.

Cliff, K., \& Wright, J. (2010). Confusing and contradictory: Considering obesity discourse and eating disorders as they shape body pedagogies in HPE. Sport, Education and Society, 15, 221-233.

Crenshaw, K. (1991). Mapping the margins: Intersectionality, identity politics, and violence against women of color. Stanford Law Review, 43, 1241-1299.

Evans, J., \& Rich, E. (2011). Body policies and body pedagogies: Every child matters in totally pedagogised schools? Journal of Education Policy, 26, 361-379. 
Feldman, M. B., \& Meyer, I. H. (2007). Eating disorders in diverse lesbian, gay, and bisexual populations. International Journal of Eating Disorders, 40, 218-226.

Foucault, M. (1978). The history of sexuality. Volume 1: An introduction (R. Hurley, Trans.). New York, NY: Pantheon Books.

Francombe-Webb, J., \& Silk, M. (2015). Young women's embodied experiences of femininity and social class. Sociology, 50, 652-672.

Gewirtz, S. (2008). "Give us a Break!" A skeptical review of contemporary discourses of lifelong learning. European Educational Research Journal 7, 414-424.

Gill, R. (2007). Postfeminist media culture: Elements of a sensibility. European Journal of Cultural Studies, 10, 147-166.

Gill, R. (2008). Culture and subjectivity in neoliberal and postfeminist times. Subjectivity, 25, 432-445.

Gill, R., \& Elias, A. S. (2014). "Awaken your incredible": Love your body discourses and postfeminist contradictions. International Journal of Media and Cultural Politics, 10, 179-188.

Grillo, T. (1995). Anti-essentialism and intersectionality: Tools to dismantle the masters' house. Berkeley Women's Law Journal, 10(16), 16-30.

Irving, L. M., \& Neumark-Sztainer, D. (2002). Integrating the prevention of eating disorders and obesity: feasible or futile? Preventive Medicine, 34, 299-309. 
Jones, R., \& Malson, H. (2013). A critical exploration of lesbian perspectives on eating disorders. Psychology and Sexuality, 4, 6274.

Kane, G. D. (2010). Revisiting gay men's body image issues: Exposing the fault lines. Review of General Psychology, 14, 311-317.

Larkin, J., \& Rice, C. (2005). Beyond "healthy eating" and "healthy weights": Harassment and the health curriculum in middle schools. Body Image, 2, 219-232.

Lebow, J., Sim, L., \& Kransdorf, L. N. (2015). Prevalence of a history of overweight and obesity in adolescents with restrictive eating disorders. Journal of Adolescent Health, 56, 19-24.

MacNeill, M., \& Rail, G. (2010). The visions, voices and moves of young 'Canadians': Exploring diversity, subjectivity and cultural constructions of fitness and health. In J. Wright \& D. Macdonald (Eds.), Young people, physical activity and the everyday (pp. 175193). London, UK: Routledge.

McPhail, D. (2013). Resisting biopedagogies of obesity in a problem population: understandings of healthy eating and healthy weight in a Newfoundland and Labrador community. Critical Public Health, 23, 289-303.

McVey, G. L., Davis, R., Tweed, S., \& Shaw, B. F. (2004). Evaluation of a school-based program designed to improve body image satisfaction, global self-esteem, and eating attitudes and behaviors: a replication study. The International Journal of Eating Disorders, 36, 1-11. 
Murnen, S. K., \& Smolak, L. (2009). Are feminist women protected from body image problems? A meta-analytic review of relevant research. Sex Roles, 60, 186-197.

O'Reilly, C., \& Sixsmith, J. (2012). From theory to policy: Reducing harms associated with the weight-centered health paradigm. Fat Studies, 1, 97-113.

Rail, G., \& Jette, S. (2015). Reflections on biopedagogies and/of public health: On bio-others, rescue missions, and social justice. Cultural Studies $\leftrightarrow$ Critical Methodologies, 15, 327-336.

Rice, C. (2007). Becoming "the fat girl": Acquisition of an unfit identity. Women's Studies International Forum, 30, 158-174.

Rice, C. (2014). Becoming women: the embodied self in image culture. Toronto: University of Toronto Press.

Rice, C. (2015). Rethinking fat: From bio- to body-becoming pedagogies. Cultural Studies $\leftrightarrow$ Critical Methodologies, 15, 387-397.

Rice, C., \& Russell, V. (2002). Embodying equity: Body image as an equity issue. Toronto, Canada: Green Dragon Press.

Rich, E. (2011). "I see her being obesed!": Public pedagogy, reality media and the obesity crisis. Health: An Interdisciplinary Journal for the Social Study of Health, Illness and Medicine, 15, 3-21. 
Saguy, A. C., \& Gruys, K. (2010). Morality and health: News media constructions of overweight and eating disorders. Social Problems, $57,231-250$.

Singh, P. (2015). Performativity and pedagogising knowledge: Globalising educational policy formation, dissemination and enactment. Journal of Education Policy, 30, 363-384.

Stice, E., Chase, A., Stormer, S., \& Appel, A. (2001). A randomized trial of a dissonance-based eating disorder prevention program. The International Journal of Eating Disorders, 29, 247-262.

Stice, E., Shaw, H., \& Marti, C. N. (2007). A meta-analytic review of eating disorder prevention programs: encouraging findings. Annual Review of Clinical Psychology, 3, 207-231.

Wilksch, S. M., \& Wade, T. D. (2013). Life Smart: a pilot study of a schoolbased program to reduce the risk of both eating disorders and obesity in young adolescent young women and boys. Journal of Pediatric Psychology, 38, 1021-1029.

Wright, J. (2009). Biopower, biopedagogies and the obesity epidemic. University of Wollongong Australia. Faculty of Education - Papers (Archive). Retrieved from http://ro.uow.edu.au/edupapers/708 